\title{
O QUE PENSAM OS ENFERMEIROS DO SAMU SOBRE O SEU PROCESSO DE TRABALHO*
}

Marilene Nonnemacher Luchtemberg ${ }^{1}$, Denise Elvira Pires de Pires²

${ }^{1}$ Enfermeira. Doutora em Enfermagem. Escola Superior de Criciúma. Criciúma, SC, Brasil.

${ }^{2}$ Enfermeira. Pós-doutorado em Ciências Sociais. Docente do Programa de Pós Graduação em Enfermagem da Universidade Federal de Santa Catarina. Florianópolis, SC, Brasil.

RESUMO: Objetivou-se identificar a percepção de enfermeiros de um Serviço de Atendimento Móvel de Urgência sobre o seu processo de trabalho em um estado da região sul do Brasil. Estudo exploratório descritivo realizado entre janeiro e março de 2014. Os dados foram coletados com 63 enfermeiros utilizando um instrumento com perguntas fechadas e abertas. Para a análise dos dados, utilizou-se a análise de conteúdo e a teorização de Karl Marx para interpretar as formulações dos enfermeiros. As categorias analisadas foram: o trabalho no Serviço de Atendimento Móvel de Urgência - a descrição das atividades, processo de trabalho no Serviço de Atendimento Móvel de Urgência e o que orienta o agir profissional. Considerando-se o entendimento de trabalho e elementos do processo de trabalho no materialismo histórico-dialético, os resultados da pesquisa aproximam-se desta fundamentação teórica. Conclui-se que reflexões obtidas, a partir das análises das categorias, podem ser úteis para a qualificação da assistência neste campo.

DESCRITORES: Ambulâncias; Serviços médicos de emergência; Enfermeiros; Trabalho.

\section{WHAT DO NURSES OF THE SAMU (MOBILE EMERGENCY CARE SERVICE) THINK ABOUT THEIR WORK PROCESS}

\begin{abstract}
The purpose of the present study was to determine the way nurses of a Mobile Emergency Care Service (SAMU) perceive their work process, in a state of the Southern region of Brazil. Descriptive-exploratory study conducted between January and March 2014. Data from 63 nurses was collected through an instrument with close-ended and open-ended questions. Content analysis and critical theorization of Karl Marx to interpret the nurses' statements. The assessed categories were work in the Mobile Emergency Care Service - description of the activities, work process at the Mobile Emergency Care Service and what guides the professional actions taken. Given the nurses' understanding of work and the elements of work process in the light of dialectical and historical materialism, the results obtained in this study were found to be connected with this theoretical foundation. It is concluded that the reflections made during the analysis of the referred categories can be useful to improve nursing care in this field.

DESCRIPTORS: Ambulances; Emergency medical services;
\end{abstract} Nurses; Work.

\section{QUÉ PIENSAN LOS ENFERMEROS DEL SAMU ACERCA DE SU PROCESO DE TRABAJO}

RESUMEN: Se objetivó identificar la percepción de enfermeros de un Servicio de Atendimiento Móvil de Urgencia sobre su proceso de trabajo en un estado de la región sur del Brasil. Estudio exploratorio descriptivo realizado entre enero y marzo de 2014. Los datos fueron obtenidos con 63 enfermeros, utilizándose un instrumento con preguntas cerradas y abiertas. Para el análisis dos datos, fue utilizado el análisis de contenido y la teorización de Karl Marx para interpretar las formulaciones de los enfermeros. Las categorías analizadas fueron: el trabajo en el Servicio de Atendimiento Móvil de Urgencia - la descripción de las actividades, proceso de trabajo en el Servicio de Atendimiento Móvil de Urgencia y lo que orienta la acción profesional. Considerándose el entendimiento de trabajo y elementos del proceso de trabajo en el materialismo histórico dialético, los resultados de la investigación se acercan de esta fundamentación teórica. Se concluye que reflexiones obtenidas por medio de los análisis de las categorías pueden ser útiles para la cualificación de la asistencia en este campo. DESCRIPTORES: Ambulancias; Servicios Médicos de Emergencia; Enfermeros; Trabajo.

*Artigo extraído da tese intitulada: Processo de Trabalho no SAMU: o que pensam os enfermeiros?. Universidade Federal de Santa Catarina, 2014.

Autor Correspondente:

Marilene Nonnemacher Luchtemberg

Escola Superior de Criciúma

R. Gonçalves Ledo, 185 - 88802-120 - Criciúma, SC, Brasil

E-mail: marilene@esucri.com.br 


\section{INTRODUÇÃO}

O Serviço de Atendimento Móvel de Urgência (SAMU) integra a Política Brasileira de Atenção às Urgências e Emergências. $O$ serviço é prestado por equipes compostas por: I) Equipe da Central de Regulação: formada por médicos reguladores, técnicos auxiliares de regulação médica, controladores de frota e radioperadores; II) Equipe das Unidades de Suporte Avançado composta por: médico, enfermeiro, motoristasocorrista; III) Equipe do Helicóptero de Suporte Avançado (Polícia Rodoviária Federal - PRF/ SAMU) composta por: médico e enfermeiro; piloto e técnico de operações especiais da PRF; e IV) Equipe da Unidade Móvel de Suporte Básico, composta por técnico de enfermagem e motorista-socorrista $^{(1)}$.

O processo de trabalho dos enfermeirost do SAMU é parte do trabalho das equipes de saúde. Estes profissionais estão presentes nas unidades de suporte avançado, na modalidade terrestre, aérea e marítima. Assumem cargos de coordenação de enfermagem e de responsabilidade técnica.

Para analisar o processo de trabalho dos enfermeiros, optou-se pela abordagem Marxista. Segundo esta abordagem, o processo de trabalho humano envolve intervenção sobre um objeto, promovendo uma transformação com vistas a atender necessidades. Este processo envolve três elementos: a) a atividade adequada a um fim, que é o próprio trabalho/a ação transformadora; b) a matéria que se aplica o trabalho, o objeto de trabalho; c) os meios de trabalho/o instrumental de trabalho ${ }^{(2)}$.

Utilizando esta teorização para análise do trabalho realizado pelos enfermeiros do SAMU, podemos inferir que o enfermeiro e o paciente após o atendimento já não são mais os mesmos. O enfermeiro presta a assistência a um indivíduo podendo envolver familiares ou grupos da comunidade. Estes por sua vez constituem o objeto de trabalho dos enfermeiros. Para realizar a ação transformadora, os enfermeiros utilizam técnicas e conhecimentos com a finalidade de salvar vidas e minimizar agravos.

Para prestar atendimento a equipe necessita de múltiplos instrumentos, os quais estão disponíveis nas unidades de suporte básico e avançado, equipadas com materiais, medicamentos, e instrumentos necessários para a prestação da

†Neste estudo enfermeiros e enfermeiras foram identificados por enfermeiros. assistência. Para realizar a assistência, a força de trabalho dos enfermeiros associa-se à dos médicos, dos técnicos de enfermagem, dos motoristas socorristas e outros já citados ${ }^{(3)}$.

O agir profissional é regulado pela legislação específica e pelo definido no campo da saúde. Destaca-se a Lei ${ }^{\circ} 7.498 / 86$ que regula o Exercício Profissional da Enfermagem. Esta estabelece que as atividades de profissionais de nível médio de enfermagem somente podem ser desempenhadas sob orientação e supervisão do enfermeiro ${ }^{(4)}$.

Neste contexto este estudo objetivou identificar a percepção dos enfermeiros do SAMU sobre o seu processo de trabalho em um estado da região sul do Brasil.

\section{MÉTODO}

Estudo exploratório descritivo envolvendo enfermeiros que atuavam no SAMU de um estado da região sul do Brasil.

Foram convidados a participar da pesquisa os 120 enfermeiros que atuavam no estado. No entanto, no momento da pesquisa, 104 profissionais estavam aptos a participar, pois havia 13 em férias e 03 em licença maternidade.

Para a coleta de dados, tendo em vista a dificuldade de acesso presencial do pesquisador aos enfermeiros que se encontram distribuídos em todo o estado, e com vistas a agilizar o acesso, optou-se por encaminhar um formulário com questões abertas e fechadas, a ser preenchido individualmente. $\mathrm{O}$ referido instrumento foi distribuído em janeiro de 2014, sendo que no início do mês de fevereiro já estava disponível em todas as oito centrais de regulação do SAMU distribuídas pelo estado. O instrumento, respondido, retornou às pesquisadoras no mês de março, totalizando 63 o que correspondeu a $60,5 \%$ do universo de enfermeiros aptos a responder a pesquisa.

Aos participantes foi enviada uma carta de apresentação explicando os propósitos do estudo e a importância da sua participação, duas vias do Termo de Consentimento Livre Esclarecido (TCLE) rubricados e o formulário. Estes documentos foram encaminhados à gerência estadual de enfermagem que encaminhou via malote às oito centrais de regulação do SAMU distribuídas pelo estado. Uma via do TCLE ficou de posse do participante e a outra retornou com $\mathrm{o}$ instrumento preenchido às pesquisadoras em envelopes lacrados, via correio ou remetidos à 
central do SAMU, os quais posteriormente foram recolhidos pelas pesquisadoras.

Todos os dispositivos constantes na Resolução $n^{\circ}$ 466, de 2012 do Conselho Nacional de Saúde, que norteiam pesquisas com seres humanos, foram respeitados ${ }^{(5)}$. O projeto foi aprovado pelo Comitê de Ética em Pesquisa da Universidade Federal de Santa Catarina (UFSC), sob o Parecer $\mathrm{n}^{\circ} 364.784$, de 12 de agosto de 2013.

Para a análise dos dados, seguiu-se os pressupostos da análise temática de conteúdo, e para a interpretação das respostas dos participantes acerca do processo de trabalho, utilizou-se o referencial teórico do materialismo histórico-dialético. O processo seguiu o fluxo: préanálise, exploração do material e tratamento dos resultados, incluindo inferência e interpretação ${ }^{(6)}$.

\section{RESULTADOS}

Os dados foram organizados em três categorias: o trabalho no SAMU - a descrição das atividades; processo de trabalho no SAMU segundo os enfermeiros; e a última categoria descreve o que orienta o agir profissional dos enfermeiros no SAMU.

\section{O trabalho no SAMU: a descrição das atividades}

Para compreender o processo de trabalho no SAMU, a ação transformadora no sentido dado por Karl Marx ao trabalho humano, descrevemos o fluxo de trabalho realizado pelos enfermeiros que atuam no SAMU. Estes dados apresentam a forma como o serviço é acionado, a composição da equipe, como o trabalho é realizado pela equipe e pelo enfermeiro até quando concluído, com quem o enfermeiro se relaciona e em quais situações. Os resultados, com o quantitativo de citações, estão apresentados no Quadro 1.

Os enfermeiros, ao serem questionados sobre como o trabalho do SAMU é acionado, $79,4 \%$ dos participantes responderam que se dá através de uma ligação ao número 192 (Central de Regulação). Na sequência, a central aciona a equipe via tablet ou telefone celular. Do total, $20,6 \%$ não responderam ao questionamento.

Sobre a composição da equipe, $100 \%$ dos participantes responderam que a equipe é composta por médico, enfermeiro e motorista socorrista. Porém, vale ressaltar que estes fazem parte da equipe da unidade de suporte avançado, e as equipes de suporte básico que representam $81,6 \%$ do conjunto de equipes, é formada por técnicos de enfermagem e motoristas socorristas.

Sobre como o trabalho é realizado pela equipe houve 69 citações, ou seja, alguns enfermeiros participaram com mais de uma citação. Deste total, $47,8 \%$ mencionaram que o trabalho é realizado dentro das suas atribuições/protocolos. Na sequência, 31,9\% disseram que o trabalho é realizado de forma dinâmica e integrada, 14,5\% disseram que o trabalho é realizado de acordo com a necessidade da vítima e por fim 5,8\% de acordo com o que diz o médico regulador.

Quando se questionou sobre como o trabalho é realizado pelo enfermeiro, houve 72 citações, destas, $41,7 \%$ referem que é de acordo com as atribuições do enfermeiro, 25\% responderam que o enfermeiro presta atendimento e organiza o atendimento, $18 \%$ que realizam o trabalho com conhecimento técnico-científico seguindo protocolos, $7 \%$ que realizam o trabalho com tranquilidade e destreza, 5,5\% com ética e 2,8\% com satisfação e muita responsabilidade.

Ao serem questionados sobre quando $\mathrm{O}$ trabalho da equipe e do enfermeiro se conclui, houve 65 citações. Destas 49,2\% responderam que é quando a equipe deixa a vítima no seu destino (casa ou serviço de saúde), $40 \%$ informaram que é quando a equipe retorna à base e o enfermeiro limpa a ambulância e repõe o material, e 10,8\% responderam que é na passagem do plantão. Portanto, praticamente $90 \%$ das citações referem que a conclusão do trabalho se dá ao finalizar o atendimento à vítima. Mesmo os $40 \%$ que informaram que o trabalho se conclui após a limpeza da ambulância e reposição dos materiais, estas atividades só poderiam ter sido realizadas após o encerramento do atendimento à vítima.

Ainda em relação a este elemento do processo de trabalho, quando questionados, especificamente, sobre qual é o produto do trabalho do SAMU e do enfermeiro do SAMU, houve 59 citações. Deste total, 55,9\% referiram que o produto é o atendimento à população em situação de urgência e emergência e 33,9\% que o produto do trabalho é salvar a vida dos pacientes. Novamente, para quase $90 \%$ dos enfermeiros o produto do trabalho do SAMU e do enfermeiro do SAMU é a assistência prestada ao indivíduo. As demais citações correspondendo a 6,8\% e $3,4 \%$, respectivamente, referem que o produto do trabalho é "o conhecimento, habilidade e agilidade" ou "o comprometimento e competência".

Quando questionados sobre os profissionais 
Quadro 1 - Fluxo de trabalho e quantitativo de respostas segundo os enfermeiros do SAMU, Santa Catarina, Brasil, 2014

\begin{tabular}{|c|c|c|}
\hline \multicolumn{3}{|c|}{ Fluxo de Trabalho } \\
\hline Como é acionado & \multicolumn{2}{|c|}{$\begin{array}{l}\text { Através de uma ligação telefônica ao número } 192 \text { e a equipe é acionada via tablet ou } \\
\text { celular (50) }\end{array}$} \\
\hline Composição da equipe & \multicolumn{2}{|l|}{ Médico, Enfermeiro, Motorista/Socorrista (63) } \\
\hline \multirow[t]{2}{*}{$\begin{array}{l}\text { Como o trabalho é } \\
\text { realizado pela equipe }\end{array}$} & $\begin{array}{l}\text { Cada um com suas atribuições/protocolos } \\
\text { (33) }\end{array}$ & $\begin{array}{l}\text { Forma dinâmica e integrada (em equipe) } \\
(22)\end{array}$ \\
\hline & $\begin{array}{l}\text { De acordo com a necessidade da vítima } \\
\text { (10) }\end{array}$ & Orientado pela regulação (4) \\
\hline \multirow{3}{*}{$\begin{array}{l}\text { Como o trabalho } \\
\text { é realizado pelo } \\
\text { enfermeiro }\end{array}$} & Dentro das nossas atribuições (30) & $\begin{array}{l}\text { Presta atendimento e organiza a situação } \\
\text { (18) }\end{array}$ \\
\hline & $\begin{array}{l}\text { Com conhecimento técnico científico } \\
\text { (protocolos) (13) }\end{array}$ & Tranquilidade, agilidade, destreza (5) \\
\hline & Com ética (4) & $\begin{array}{l}\text { Com satisfação e muita responsabilidade } \\
(2)\end{array}$ \\
\hline \multirow[t]{2}{*}{$\begin{array}{l}\text { Quando o trabalho da } \\
\text { equipe e do enfermeiro } \\
\text { se conclui }\end{array}$} & $\begin{array}{l}\text { Quando deixamos a vítima no seu destino } \\
\text { (casa, serviço de saúde) (32) }\end{array}$ & $\begin{array}{l}\text { Ao chegar à base limpar, a ambulância e } \\
\text { repor materiais utilizados na ocorrência } \\
(26)\end{array}$ \\
\hline & Na passagem do plantão (7) & $--\cdot-\cdot-$ \\
\hline \multirow{11}{*}{$\begin{array}{l}\text { Com quem } \\
\text { enfermeiros } \\
\text { relacionam }\end{array}$} & Médico (53) & Motorista/socorrista (51) \\
\hline & Enfermeiros (39) & Técnico de enfermagem (27) \\
\hline & Equipe hospitalar (19) & Bombeiros (18) \\
\hline & Policiais (PRF, PM, PC, GM*) (16) & Radio operador (13) \\
\hline & Técnico auxiliar de regulação médica (12) & Téc. administrativos (5) \\
\hline & Serviços gerais (4) & Coordenação (4) \\
\hline & Farmacêutico (4) & Profissionais de Pronto Atendimento (3) \\
\hline & Psicólogos (3) & Instituto Médico Legal (2) \\
\hline & Assistente social (2) & Nutricionista (1) \\
\hline & Com trabalhadores dos presídios (1) & Funcionários Públicos (1) \\
\hline & Educador (1) & $\begin{array}{ll}--\cdot-- \\
\end{array}$ \\
\hline \multirow{6}{*}{$\begin{array}{l}\text { Em quais situações } \\
\text { ocorrem relações com } \\
\text { outros trabalhadores } \\
\text { ou serviços }\end{array}$} & Nos atendimentos/ocorrências (38) & Em diversas situações (16) \\
\hline & Nas transferências (12) & Na Base (regulação) (10) \\
\hline & Nos hospitais (7) & No Pronto Atendimento (4) \\
\hline & No apoio aos bombeiros (2) & Durante o plantão (2) \\
\hline & Nas reuniões entre equipes (2) & Na ocorrência de óbitos (1) \\
\hline & Durante as capacitações (1) & ------- \\
\hline
\end{tabular}

e trabalhadores com os quais os enfermeiros do SAMU se relacionam, houve 279 citações, distribuídos em 21 grupos de profissionais e trabalhadores. Os mais citados foram: o profissional médico com $19 \%$, motorista socorrista com $18,3 \%$, com os próprios enfermeiros $14 \%$, com os técnicos de enfermagem $9,7 \%$, com a equipe hospitalar 6,8\%, com o Corpo de Bombeiros 6,5\%, com os Policiais (Rodoviária Federal, Militar, Civil e Guarda Municipal) 5,7\%, com o rádio operador $4,6 \%$, com o técnico auxiliar de regulação médica $4,3 \%$, com o técnico administrativo $1,8 \%$. As demais 26 citações distribuídas em 6 grupos de trabalhadores representam 9,3\%.

O relacionamento dos enfermeiros com os vários profissionais e trabalhadores ocorre em diversas situações. Das onze diferentes situações de inter-relação com outros grupos de trabalhadores, a mais citada, com $40 \%$, foi nos atendimentos/ocorrências. Outras situações ou locais mencionados foram: nas transferências $12,6 \%$, na base/regulação $10,5 \%$, nos hospitais $7,4 \%$ e nas unidades de pronto atendimento $4,2 \%$. A maioria das citações sobre os relacionamentos dos enfermeiros com os demais profissionais e 
trabalhadores ocorrem durante os atendimentos aos pacientes. Poucas são as situações em que esses relacionamentos ocorrem em ambientes sem a presença da vítima.

\section{Processo de trabalho no SAMU segundo os} enfermeiros
No Quadro 2, descrevemos a necessidade geradora do trabalho do SAMU segundo os enfermeiros, a quem se dirige o trabalho da equipe e do enfermeiro, qual a finalidade do trabalho e quais os instrumentos de trabalho. Estes dados estão apresentados com o quantitativo das citações.

Quadro 2 - Elementos do processo de trabalho e quantitativo de respostas dos enfermeiros do SAMU, Santa Catarina, Brasil, 2014

\section{Elementos do Processo de Trabalho dos enfermeiros no SAMU}

\begin{tabular}{lll}
\hline $\begin{array}{l}\text { Necessidade geradora } \\
\text { do trabalho do SAMU } \\
\text { e do enfermeiro }\end{array}$ & Situações de Urgência e Emergência (34) & $\begin{array}{l}\text { População que necessita de atendimento } \\
(17)\end{array}$ \\
\cline { 2 - 3 } & Transferências Inter-hospitalares (9) & $\begin{array}{l}\text { Solicitação de atendimento vinda da } \\
\text { Regulação (5) }\end{array}$ \\
\cline { 2 - 3 } & Acidentes de Trânsito (5) & $\begin{array}{l}\text { Necessidades de orientações em relação } \\
\text { a prevenção e promoção (2) }\end{array}$ \\
\cline { 2 - 3 } & Trabalho de Parto (1) & Violência (1) \\
\cline { 2 - 3 } & Falta de resolubilidade dos serviços de saúde (1) \\
\hline Objeto de trabalho do & A população em geral com risco de vida & Os hospitais (2) \\
SAMU e do enfermeiro & $(58)$ &
\end{tabular}

SAMU e do enfermeiro (58)

A cena, a equipe, a regulação, a O comércio (1)

coordenação (2)

Qual a finalidade do Prestar assistência à população em Realizar transferência (6)

trabalho do SAMU situação de urgência e emergência

e do enfermeiro do (diminuindo o agravo, minimizando

SAMU

sequelas (59)

Atender e liberar no próprio local (3)

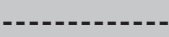

Qual o produto do Atendimento à população em situação de Salvar vida dos pacientes (20)

trabalho do SAMU urgência e emergência (33)

e do enfermeiro do Conhecimento, habilidade, agilidade (4) Comprometimento e competência (2)

SAMU

\begin{tabular}{|c|c|c|}
\hline \multirow{16}{*}{$\begin{array}{l}\text { Quais os instrumentos } \\
\text { de trabalho }\end{array}$} & Ventilador Mecânico (21) & Bomba de Infusão (18) \\
\hline & Conhecimento técnico científico (17) & Materiais e medicamentos (15) \\
\hline & Instrumentos disponíveis na Viatura (13) & Desfibrilador/Cardioversor (13) \\
\hline & Monitor Cardíaco (12) & $\begin{array}{l}\text { Materiais para Imobilização/maca rígida } \\
\text { (11) }\end{array}$ \\
\hline & Capacitações (10) & Aparelho de Pressão Arterial (9) \\
\hline & Evolução de Enfermagem (8) & Cateteres para Punção (8) \\
\hline & Protocolos de atendimento (8) & Tablet (6) \\
\hline & $\begin{array}{llll}\text { Sistematização } & \text { da } & \text { Assistência } & \text { de } \\
\text { Enfermagem (6) }\end{array}$ & Oxímetro (6) \\
\hline & Aparelho para Hemoglicoteste (4) & Sonda vesical e nasogástrica (4) \\
\hline & Eletrocardiograma (4) & Incubadora (4) \\
\hline & Material para curativos (3) & Livros e revistas científicas (3) \\
\hline & Telefone celular (3) & Maca retrátil (3) \\
\hline & Recursos humanos (3) & Termômetro (2) \\
\hline & Lanterna (2) & Viaturas (1) \\
\hline & Material para Sutura (1) & Ambú (1) \\
\hline & Drenagem de tórax (1) & Fichas de atendimento (1) \\
\hline
\end{tabular}


No que diz respeito aos elementos do processo de trabalho dos enfermeiros do SAMU, o primeiro questionamento foi saber a necessidade geradora do trabalho do SAMU e dos enfermeiros, sendo descritas nove situações. A mais citada foi a situação de urgência e emergência com $45 \%$.

$\mathrm{Na}$ sequência, encontra-se uma formulação genérica de que a necessidade geradora é a existência de um contingente da população que necessita de atendimento com 22,7\%, seguida de transferências inter-hospitalares com $12 \%$. A seguir estão duas citações de que a necessidade geradora é a regulação médica e os acidentes de trânsito, ambas com $6,7 \%$. As demais citações (5) representam $6,6 \%$.

Em relação à finalidade do trabalho do SAMU e do enfermeiro do SAMU, identificouse 68 citações, destas $86,8 \%$ mencionaram que é prestar assistência à população em situação de urgência e emergência diminuindo o agravo e minimizando sequelas. Para $8,8 \%$, a finalidade é realizar transferências inter-hospitalares e para $4,4 \%$ atender e liberar no próprio local.

Ao serem questionados sobre os instrumentos de trabalho utilizados pelos enfermeiros, houve 221 citações, indicando 32 tipos de instrumentos. Os mais citados foram ventilador mecânico com 9,5\%, bomba de infusão $8,1 \%$, com $7,7 \%$ conhecimento técnico-científico disponível, com $6,8 \%$ materiais e medicamentos, com 5,9\% instrumentos disponíveis na viatura, e com o mesmo percentual desfibrilador/cardioversor, com $5,4 \%$ monitor cardíaco, com $5 \%$ materiais para imobilização/maca rígida, com 4,5\% capacitação, $4,1 \%$ aparelho de pressão arterial. Ainda foram citados diversos instrumentos como cateteres para punção, tablet, oxímetro e outros.

Ainda em relação aos instrumentos de trabalho, no que diz respeito à adequação, quantidade e condições para o uso, as respostas obtidas estão apresentadas no Quadro 3.

Das 60 citações relacionadas à qualidade e suficiência dos instrumentos de trabalho, 71,7\% informaram que são suficientes, 23,3\% informaram que às vezes são suficientes e apenas para $5 \%$ não são suficientes. Sobre o questionamento se são adequados, 74,6\% responderam afirmativamente, $22 \%$ às vezes e $3,4 \%$ não são adequados. Quando questionados se funcionam, $78 \%$ referem que funcionam e $22 \%$ que às vezes funcionam.

Quando questionados especificamente se as condições de trabalho são adequadas, 59 enfermeiros responderam a este questionamento,
Quadro 3 - Sobre a adequação, suficiência e condições dos instrumentos de trabalho disponíveis no SAMU, segundo os enfermeiros, Santa Catarina, Brasil, 2014

\section{Sobre os Instrumentos de Trabalho}

\begin{tabular}{lcccc}
\hline $\begin{array}{l}\text { Instrumentos necessários } \\
\text { para a realização do seu }\end{array}$ & & Não & Às \\
trabalho como enfermeiro & & & vezes \\
do SAMU & 43 & 3 & 14 \\
\hline São Suficientes & 44 & 2 & 13 \\
\hline São Adequadas & 46 & -- & 13 \\
\hline Funcionam & & &
\end{tabular}

dos quais, $81,4 \%$ informaram que sim, e $18,6 \%$ informaram não serem adequadas.

No que diz respeito às relações de trabalho, 54 enfermeiros mostraram a predominância de boas relações de trabalho, correspondendo a $87,1 \%$ das respostas relativas a este quesito. Um percentual de $11,3 \%$ das respostas, correspondendo a sete citações, responderam que as relações não são adequadas. Apenas 1,6\%, correspondendo a uma citação, respondeu que às vezes.

\section{$O$ que orienta o agir profissional dos enfermeiros no SAMU}

Com vistas a compreender a percepção dos enfermeiros sobre o seu trabalho no sentido de inter-relação entre o papel prescrito pela Política Nacional de Atenção as Urgências (PNAU) e o que está definido na legislação profissional, os mesmos foram questionados sobre as políticas de urgência vigentes no estado e no país, a Lei do Exercício Profissional da Enfermagem e as Resoluções do Conselho Federal de Enfermagem (COFEN) relativas ao trabalho do enfermeiro no SAMU.

As respostas dos enfermeiros, com a respectiva especificação numérica, estão descritas no Quadro 4.

Quando questionados se conheciam a Lei do Exercício Profissional, 95\% responderam que conhecem a legislação, e 5\% que desconhecem. Quando questionados se a legislação profissional influencia no seu trabalho, 98,2\% informaram que influencia, e apenas 1,8\%, que não influencia.

\section{DISCUSSÃO}

A necessidade geradora do trabalho do SAMU é a existência de um cidadão em situação de urgência ou emergência. No entanto, a solicitação de atendimento a este cidadão pode ser uma situação de urgência/emergência ou 
Quadro 4 - O que orienta o agir profissional dos enfermeiros do SAMU, Santa Catarina, Brasil, 2014

\section{Sobre o agir profissional}

\begin{tabular}{|c|c|c|c|}
\hline & Sim & Não & $\begin{array}{c}\text { Às } \\
\text { vezes }\end{array}$ \\
\hline $\begin{array}{l}\text { Você conhece as Políticas de } \\
\text { Urgência vigentes no estado e } \\
\text { no país? }\end{array}$ & 58 & 2 & - \\
\hline $\begin{array}{l}\text { Elas influenciam no seu } \\
\text { trabalho? }\end{array}$ & 58 & 2 & - \\
\hline $\begin{array}{l}\text { Você conhece a Lei do } \\
\text { Exercício Profissional da } \\
\text { Enfermagem e as Resoluções } \\
\text { do COFEN referentes ao } \\
\text { trabalho da enfermagem em } \\
\text { urgência e emergência e no } \\
\text { SAMU? }\end{array}$ & 57 & 3 & - \\
\hline $\begin{array}{l}\text { Elas influenciam no seu } \\
\text { trabalho? }\end{array}$ & 55 & 1 & - \\
\hline
\end{tabular}

a chamada do SAMU pode ser inadequada ou imprópria como é o caso dos trotes. Segundo estudo realizado em 2012 no Estado de Santa Catarina, acerca das chamadas do SAMU que não geraram atendimento, encontrou-se que os trotes representavam $45,2 \%$ das chamadas no ano de 2007, 31,8\% em 2008, 23\% em 2009 e 12,3\% em 2010. Apesar da diminuição no período, esta ocorrência ainda é altamente expressiva ${ }^{(7)}$.

Ao descreverem "como o trabalho da equipe é realizado", $31,9 \%$ dos participantes da pesquisa mencionaram que o mesmo é realizado de "forma dinâmica e integrada (em equipe)", entendendo o trabalho do enfermeiro como integrante da equipe. Os participantes da pesquisa parecem reconhecer que a integração das diferentes formações e saberes é necessária para a assistência em emergência. Outro aspecto também mencionado de "que o trabalho nesta área é dinâmico", sinaliza para o reconhecimento da imprevisibilidade típica das ações de emergência.

Esse resultado aproxima-se do encontrado em outro estudo $^{(8)}$, de que o trabalho em equipe no atendimento pré-hospitalar favorece a realização de ações integradas, agilizando o atendimento às vítimas. Transcende relações hierárquicas entre os profissionais e trabalhadores que compõem as equipes e proporciona rapidez e qualidade no atendimento.

O trabalho da enfermagem desenvolvese, na maioria das vezes, de forma coletiva e em colaboração com outros profissionais e trabalhadores do campo da saúde. Neste estudo vimos que os enfermeiros do SAMU se relacionam com outros profissionais de enfermagem e de saúde, e também com outros grupos de trabalhadores como é o caso dos policiais, educadores, técnicos administrativos, entre outros ${ }^{(9)}$.

Trata-se de um trabalho complexo envolvendo relações. E, visto que para 11,1\% as relações não são adequadas, assume importância a capacitação do enfermeiro para as relações interpessoais. Nesta área, em que a cooperação é fundamental para a qualidade e segurança dos cuidados prestados, dificuldades no relacionamento interpessoal certamente comprometem o trabalho da equipe.

Em relação à necessidade geradora do trabalho do SAMU e dos enfermeiros, pode-se generalizar que todas as situações mencionadas estão relacionadas à necessidade de atendimento profissional a uma pessoa em situação de urgência e emergência.

Quando questionados "a quem se dirige o trabalho do SAMU e do enfermeiro do SAMU", das 63 citações, 92\% responderam que o trabalho se dirige à população em geral com risco de vida, ou seja, as pessoas (individual ou coletivamente) são o objeto de trabalho dos enfermeiros do SAMU. Este achado aproxima-se do mencionado na literatura de que o objeto de trabalho dos profissionais de enfermagem são os seres humanos na forma individual ou coletiva precisando de ações curativas, preventivas ou do âmbito da promoção da saúde ${ }^{(3)}$. As demais citações (05) representando $8 \%$, ao tratarem do objeto de trabalho do SAMU e dos enfermeiros, responderam de modo diferenciado do mencionado na literatura sobre o processo de trabalho humano e na saúde ${ }^{(2-3)}$.

$\mathrm{Na}$ teorização sobre processo de trabalho humano, a finalidade orienta o percurso e o que se pretende obter ao final do processo de transformação, portanto, o produto do trabalho corresponde à formulação objetiva da finalidade $^{(2-10)}$. Essa abordagem teórica refere ainda que em grande parte das atividades do setor de serviços, o produto do trabalho tem características diferenciadas do produto resultante da produção material industrial, ou seja, o trabalho conclui-se com a realização da atividade, como é o caso do trabalho em saúde e educação ${ }^{(2-3)}$.

Em relação ao produto do trabalho do SAMU e do enfermeiro do SAMU, os participantes responderam majoritariamente que é a assistência prestada ao indivíduo, o que corresponde à teoria 
do processo de trabalho ${ }^{(2-3)}$. Ou seja, o produto do trabalho dos enfermeiros do SAMU é o serviço prestado, a assistência prestada, não é algo palpável, não é um produto material. A assistência é produzida e consumida simultaneamente. As demais citações, minoritárias, referem que o produto do trabalho é "o conhecimento, habilidade e agilidade" ou "o comprometimento e competência". Nestes casos, trata-se de atributos ou requisitos relacionados à força de trabalho distanciando-se da teoria do processo de trabalho. Este achado pode estar relacionado com dificuldades no entendimento da questão formulada no instrumento de coleta de dados, uma vez que os formulários foram preenchidos sem a participação dos pesquisadores.

Cabe destacar a referência ao conhecimento como instrumento de trabalho, o que também corresponde à definição de instrumento de trabalho encontrada na literatura ${ }^{(3)}$. Neste aspecto destaca-se a menção ao conhecimento acerca da Sistematização da Assistência de Enfermagem (SAE) e da evolução de enfermagem, que é parte da $\mathrm{SAE}$, e os protocolos de atendimento.

\begin{abstract}
o processo de trabalho dos profissionais de saúde tem como finalidade - ação terapêutica de saúde; como objeto - o indivíduo ou grupos doentes, sadios ou expostos a risco, necessitando medidas de curativas, preservar a saúde ou prevenir doenças; como instrumental de trabalho - os instrumentos e as condutas que representam o nível técnico do conhecimento que é o saber de saúde e o produto final é a própria prestação da assistência de saúde que é produzida no mesmo momento que é consumida ${ }^{(3: 161)}$.
\end{abstract}

Os dados mostraram que, majoritariamente, os participantes consideraram que os instrumentos de trabalho são adequados, suficientes e estão disponíveis em boas condições para o uso. Apenas um grupo inferior a 5\% respondeu de forma negativa a estes três aspectos. $\mathrm{O}$ resultado demonstra confiabilidade e segurança dos enfermeiros no que diz respeito aos instrumentos necessários para a realização do seu trabalho.

No que diz respeito às relações e condições de trabalho, os resultados sinalizam para um cenário majoritariamente positivo, diferenciando-se do registrado na literatura brasileira sobre condições de trabalho na saúde e enfermagem.

Quando os enfermeiros são impedidos de realizarem suas atividades, eles se vêem diante do confronto entre agir, de um lado, em função das necessidades de saúde da população, transgredindo ou inventando, e, de outro, das imposições da norma que limitam sua atuação ${ }^{(11)}$.
Relações e condições de trabalho são fundamentais para a equipe, visto que diariamente realizam muitas atividades, muitas destas de alta complexidade, colocando muitas vezes em risco a própria vida dos integrantes da equipe ${ }^{(12)}$.

Quando questionados sobre o que orienta o agir profissional e se os enfermeiros conhecem as Políticas de Urgência vigentes no estado e no país, 60 dos participantes responderam ao questionamento. Deste total, $96,7 \%$ responderam que conhecem e 3,3\% que não conhecem. Os mesmos percentuais correspondem ao respondido em relação à influência no seu trabalho da macro política para a área. Ou seja, a política prescrita tem um papel significativo na definição do que fazer e do como fazer dos enfermeiros.

Os resultados mostram, ainda, que os enfermeiros conhecem tanto as políticas de atenção às urgências quanto a legislação profissional. Sendo possível perceber, também, que fazem uma relação entre o seu fazer e a legislação vigente. No entanto, a maior influência na forma de realização do seu trabalho é política de saúde para a área. Ou seja, o fazer dos enfermeiros é orientado, predominantemente, pelos protocolos e parâmetros definidos nas Políticas de Urgência e Emergência vigentes no país e menos pela legislação da profissão.

A literatura registra a importância dos protocolos na orientação do fazer cotidiano. Segundo o disposto no Prehospital Treatment Protocols General Operating Procedures da cidade de Nova York, os protocolos foram desenvolvidos para garantir e padronizar o atendimento préhospitalar às vítimas em situação de urgência e emergência garantindo qualidade na assistência prestada $^{(13)}$.

Sobre a composição das equipes, a legislação profissional e a política de saúde para a área estabelecem quem são os componentes da equipe e as atribuições de cada um. Neste quesito, também se verificou o predomínio da orientação do prescrito na política de saúde, uma vez que, nas equipes de suporte básico, no estado onde se realizou o estudo, não há a presença do enfermeiro. Isto é inadequado ao prescrito na Legislação Profissional Lei $n^{\circ} 7.498 / 86$ e na Resolução COFEN no $375 / 2011^{(14)}$, fato que acontece sem que os enfermeiros questionem o não cumprimento do estabelecido na legislação profissional.

No que diz respeito à influência da 
legislação profissional, houve predomínio do reconhecimento das práticas de cuidado, e em segundo lugar das atividades do tipo gerencial. A literatura registra que o trabalho da enfermagem possui três dimensões: o cuidar, o gerenciar e educar ${ }^{(11)}$. Ao tratar do como o trabalho é realizado pelo enfermeiro, os participantes da pesquisa mencionaram ações de cuidado ("presta atendimento") e do tipo gerencial ("organiza a situação" para o cuidado). As ações de cunho educativo e o desenvolvimento de ações específicas da enfermagem, como é o caso da sistematização da assistência, assim como a problematização da necessidade da presença dos enfermeiros, na composição de todas as equipes que realizam atividades de enfermagem, foram pouco ou não foram mencionadas.

O agir orientado pelo prescrito na legislação específica do núcleo profissional e nos conhecimentos formulados pela profissão constroem um requisito importante para a visibilidade do seu fazer, no conjunto do trabalho em saúde.

Ao olhar para o trabalho de enfermagem no SAMU, cabe ressaltar que o SAMU é um espaço em construção(15). Embora possua diretrizes nacionais pré-estabelecidas que direcionem suas práticas, cada serviço implantado procura adaptar-se às suas realidades locais.

\section{CONSIDERAÇÕES FINAIS}

O enfermeiro, na sua atividade no SAMU, relaciona-se com um grande número de profissionais da saúde e trabalhadores de diferentes áreas e em diversas situações. Um dos requisitos para o bom atendimento do enfermeiro na equipe do SAMU está ligado às formas e efetividade das relações estabelecidas no âmbito do trabalho coletivo.

Quanto aos elementos do processo de trabalho dos enfermeiros no SAMU, a maioria descreveu que a necessidade geradora do trabalho são as situações de urgência e emergência das pessoas. Que o objeto de trabalho é a população com risco de vida. Que a finalidade do trabalho é prestar atendimento/assistência à população em situação de urgência e emergência e que o produto do trabalho é o atendimento realizado as pessoas. Evidenciou-se ainda que, para a maioria dos participantes da pesquisa, os instrumentos de trabalho são suficientes, adequados e funcionam. Considerando-se o entendimento de trabalho e elementos do processo de trabalho do materialismo histórico-dialético, os resultados da pesquisa aproximam-se desta fundamentação teórica.

Sugerimos que, durante as capacitações, sejam realizados momentos de reflexão sobre o processo de trabalho da enfermagem na saúde e no SAMU, fortalecendo o entendimento dos enfermeiros e propiciando reflexão ampliada do conjunto da equipe de enfermagem e de saúde acerca do processo de trabalho do SAMU. Essa reflexão poderá contribuir para o entendimento da complexidade deste trabalho, das interfaces entre as diversas profissões e entre os diferentes exercentes da profissão de enfermagem.

Lembrando sempre que este é um trabalho realizado em equipe com diferentes profissões e trabalhadores colaborando para o resultado. Portanto, refletir sobre o processo de trabalho contribui para a melhora da qualidade da assistência, tanto da enfermagem quanto da equipe do SAMU.

\section{REFERÊNCIAS}

1. Santa Catarina. Secretaria de Estado da Saúde. Serviço de Atendimento Móvel de Urgência (SAMU). Regimento Interno - Samu 192/SC. [Acesso em 18 jun 2014]. Disponível: http://samu.saude.sc.gov. br/phocadownload/Rotinas/Rotinas_Estaduais/ regimento_interno_samusc.pdf

2. Marx K. O capital. [Livro 1 - Coleção: Marx \& Engels]. Tradução de Rubens Enderle. São Paulo: Boitempo; 2013.

3. Pires DEP. Reestruturação produtiva e trabalho em saúde no Brasil. 2. ed. Annablume; 2008.

4. Conselho Federal de Enfermagem. Lei $n^{\circ} 7.498$, de 25 de junho de 1986. Dispõe sobre a regulamentação do exercício da Enfermagem e dá outras providências. Brasília. COFEN: 1986.

5. Conselho Nacional de Saúde (BR). Resolução $n^{\circ}$ 466, de 12 de dezembro de 2012 - Aprovar as seguintes diretrizes e normas regulamentadoras de pesquisas envolvendo seres humanos. [Internet] 12 de dezembro [acesso em 01 abr 2014]. Disponível: http://conselho. saude.gov.br/resolucoes/2012/Reso466.pdf

6. Minayo MCS. Pesquisa Social: teoria, método e criatividade. 31ªed. Petrópolis, RJ: Vozes, 2012.

7. Luchtemberg MN, Pires DEP, Schoeller SD, Possamai FP. Análise de chamadas do Serviço de Atendimento Móvel de Urgência de uma capital brasileira. Rev Rene. 2014; 15(6):925-32. 
8. Pereira WAP, Lima MADS. O trabalho em equipe no atendimento pré-hospitalar à vítima de acidente de trânsito. Rev Esc Enferm., USP. 2009; 43(2):319-26.

9. Pires DEP. Transformações necessárias para o avanço da enfermagem como ciência do cuidar. Rev Bras Enferm. 2013; 66(esp):39-44.

10. Leopardi MT, Gelbcke FL, Ramos FRS. Cuidado: objeto de trabalho ou objeto epistemológico da enfermagem. Texto \& Contexto Enferm. 2001: 10(1):3249.

11. Bertoncini JH, Pires DE, Scherer MDA. Condições de trabalho e renormalizações nas atividades das enfermeiras na saúde da família. Trab. Educ. Saúde [Internet]. 2011; 9(supl.1). [acesso em 26 mar 2014]. Disponível: http://dx.doi.org/10.1590/S198177462011000400008

12. Soares EG. Singularidades do trabalho gerencial da enfermeira no contexto do Serviço de Atendimento Móvel de Urgência em Minas Gerais [dissertação]. Belo Horizonte (MG): Universidade Federal de Minas Gerais; 2009.

13. Regional Emergency Medical Advisory Committee (REMAC). New York City. Prehospital treatment protocols general operating procedures. July, 2012 [acesso em 28 ago 2014]. Disponível: http:// www.sinaiem.org/files/ems/General_Operating _ Procedures_July_2012_v07012012.pdf

14. Conselho Federal de Enfermagem (COFEN). Resolução COFEN no 375, de 2011 - Dispõe sobre a presença do Enfermeiro no Atendimento PréHospitalar e Inter-Hospitalar, em situações de risco conhecido ou desconhecido [acesso em 26 mar 2014] Disponível: http://novo.portalcofen.gov.br/resoluocofen-n-3752011_6500.html

15. Stumm EMF, Ribeiro G, Kirchner RMK, LORO MM, Schmidt CL, Piovesan R. Avaliação da saúde e qualidade de vida: profissionais de um SAMU. Cogitare enferm 2009; 14(4):620-7. 